\title{
CHAPTER ।
}

\section{Introduction}

\section{Ann Jones, Eileen Scanlon and Rebecca Ferguson}

This chapter forms the introduction to the book, "Educational Visions" and describes the nature of the book. It presents the four principles or visions which inform the work of the Computers and Learning research group (CALRG) and are reflected in this book, and then provides the context with a discussion of the innovative nature of the early Open University. The CALRG is then described briefly before the introduction of a further framework used in the book to analyse the factors that make educational innovations successful, the Beyond Prototypes model. The last section describes the organisation and contents of the rest of the book.

\section{Introduction}

This book, "Educational Visions", informs future developments in educational technology, by reviewing the history of computers and education, covering themes including learning analytics and design, inquiry learning, accessibility and learning at scale. The lessons from these developments, which evolve, recur and adapt over time give an indication of the future in the field. The book informs readers about what is already known and demonstrates how they can use this work themselves.

"Educational Visions" is based on the research of the Computers and Learning research group (CALRG). Based at The Open Unversity, CALRG is the

How to cite this book chapter:

Jones, A., Scanlon, E. and Ferguson, R. 2019. Introduction. In: Ferguson, R., Jones, A. and Scanlon, E. (eds). Educational Visions: Lessons from 40 years of innovation. Pp. 1-12. London: Ubiquity Press. DOI: https://doi.org/10.5334/bcg.a. License: CC-BY 4.0 
longest-running UK research group in the field of educational technologyy. The Open University celebrated its 50th birthday in 2019, whilst the research group recently celebrated its $40^{\text {th }}$ anniversary. The production of the book drew on the CALRG's $40^{\text {th }}$-birthday celebrations and conference to extract themes and generate content of interest to a broad audience.

The core principles of the approach to educational technology reflected in this book are:

1 Teams can successfully teach any number of students at a distance

2 Learning is accessible for everyone

3 Teaching is adapted to meet learners' needs

4 Learners engage enthusiastically with STEM learning.

These four principles give the research a practical emphasis linked to the application of educational technology to the benefit of learners. The principles also form the visions that are discussed and considered in the book. "Educational Visions" traces 40 years of research in this area, showing how these four visions are being achieved, identifying challenges that have been overcome; those that still remain, and extracting general themes in educational technology.

The structure of the book aligns with these four visions. In each case, the lead author on one chapter is a researcher with a global reputation, who examines the foundations of work towards this vision and how that work has developed over 40 years. A second chapter related to the vision is authored by researchers currently active in this field, describing current work and future directions. This approach allows for a balance between historical analysis and current thematic application.

The structure of each chapter is also related to a framework (Beyond Prototypes) which explains why educational technology initiatives worldwide succeed and why they often fail. This framework highlights that initiatives only succeed if they are guided by a vision and if they take account of the whole complex system of interacting factors that impact on educational technology (pedagogy, technical aspects, ecology of practices, technical context, student community, teacher community, technical communities, pedagogic research community, revenue generation, environment, policy context and funding). A fuller description of this framework and a graphical representation are provided further on in this introductory chapter and chapter authors use this framework as a recurring theme. The aim is not only to introduce successful educational technology projects but also to make it clear why they are successful when so many others are not.

Each chapter includes examples and/or case studies of significant work, the effect this work has had and its implications for the future. These examples include FutureLearn (a MOOC platform with more than ten million learners), the Conversational Framework (widely used to structure and understand online teaching and learning), iSpot (used internationally by citizen scientists) and 
learning analytics tools. The remainder of this chapter briefly introduces The Open University, its mission, the CAL research group and the Beyond Prototypes Framework before offering some comments on the chapters that follow.

\section{The Open University}

The Open University was established in the UK in 1969 - and celebrated its $50^{\text {th }}$ anniversary in 2019. Its mission was and still is to be open to people, places, methods and ideas. During the 1960s, only a small percentage of the UK population attended university. In 1970, a year after the OU started, but before courses were available, the figure was $8.4 \%$. A primary aim for The Open University was to extend access to higher education to a much wider population. While he was leader of the British Labour Party, Harold Wilson wrote an outline for the 'university of the air' and the Labour Party's 1966 manifesto included a commitment to establish such a university - building on the idea that the then relatively new technologies: radio, film and television, could bring university education within reach of a much larger audience. Once he was Prime Minister, Wilson appointed Jennie Lee as Arts Minister and to take charge of the project.

The Open University (OU) Charter was signed in April 1969 and by 1972 the university had 36,000 students, increasing to 72,000 by 1979 when 130 undergraduate courses were offered. The OU's core vision and mission, to be open to people and places, methods and ideas, has not changed significantly during its 50 years.

\section{Open to people and places}

OU courses originally consisted of written course materials, sent out by post to students who studied part time. In addition, through a partnership set up with the $\mathrm{OU}, \mathrm{BBC}$ (British Broadcasting Corporation) programmes were also made and broadcast in non-peak broadcasting times. Today, the BBC no longer produces broadcast programmes for OU courses, but the two organisations still work in partnership, co-producing programmes for all $\mathrm{BBC} \mathrm{tv}$, radio, digital and online channels/platforms. Printed course materials still play a role, but much is online.

Students were allocated to regional centres and to tutors who worked in the geographical areas associated with these centres. The tutors supported the students' work, marked their assignments and held tutorials at local centres during the evenings or on Saturdays. No qualifications were needed in order to start a course with The Open University: a radical idea at the time.

Generally, students were able to study wherever they lived in the UK and even when working abroad. Since then there has been a growth in students working from non-UK locations although it is not always possible to take courses from anywhere in the world. 


\section{Open to methods}

The university pioneered new approaches to teaching, especially in STEM (Science, Technology, Engineering and Maths) areas where students did not have a traditional laboratory to hand. The idea of the Home Experiment Kit was developed. This involved posting out home chemistry sets, fruit-flies and, more recently, home computers. The very first science Home Experiment Kit included a small, compact microscope. Further examples are described in Chapter 8.

Residential schools run at traditional university campuses were set up where students could use laboratories, have face-to-face lectures, and work collaboratively on projects. However, the first Chancellor of the OU also foresaw the importance of computers:

I predict that before long actual broadcasting will form only a small part of the University's output. The world is caught in a communications revolution, the effects of which will go beyond those of the Industrial Revolution of two centuries ago. .... As the steam engine was to the first revolution, so the computer is to the second." (Crowther, 1969)

Extract from Speech by Lord Crowther, first Chancellor of The Open University at the presentation of the Charter, 23rd July 1969.

\section{Open to ideas}

Probably the earliest 'big' idea was that of 'course teams' that would develop and produce courses for the students. In addition to content specialists, these included editors, administrators and educational technologists. Course materials underwent several drafts, which were commented on in course team meetings. Another significant example of the OU being open to ideas was its decision to develop a partnership with the BBC in 1971. This early collaboration meant that the programmes used in OU courses were made by BBC producers, in conjunction with academics, and so were able to benefit from the high production values of the $\mathrm{BBC}$ as well as including ingenious ways of helping students to visualise complex phenomena.

Modern technologies were used from very early days as the University developed ways of teaching science at a distance. A media mix that was heavily text based also included broadcast TV, audio and, from the mid 1970s, the use of computers. From the very beginning, the need for advising the University on the role of educational technology was acknowledged. A paper by the first Vice Chancellor, Lord Walter Perry, to the Planning Committee in July 1969 emphasised that Open University staff should include those with skills in "all the modern methods of educational technology” (Perry, 1969). By March 1970, the Institute of Educational Technology (IET) had been established. One of the 
IET's roles was to "provide the Course Teams with continuous diagnostic feedback as a basis for remedial guidance, revision and recycling”.

\section{The CAL research group}

The Computers and Learning research group (CALRG) was set up in 1979: housed in IET with founding members located in IET, Psychology and Computing. The first objective of the CAL research group was "to carry out a coordinated programme of research into ways computers can be used to improve the quality of education" (Jones and Scanlon, 1981). In their later edited book, Jones, Scanlon and O'Shea, (1987) explained that all the work described within the book "had a distance education (or training) setting in mind" (Preface, p.x), hence there was not only a strong commitment to researching teaching, but also a desire to understand how technology could improve teaching and learning within the distance learning context of the OU.

From the beginning, a significant part of the CAL research group's work was carried out by $\mathrm{PhD}$ students: both full time and part time. Members of the group were drawn from across the OU and were involved in the University's teaching in various ways: as authors, critical commentators, and evaluators, who shared "a strong commitment to improving education in general and distance education in particular by the application of new information technologies" (Jones, Scanlon and O'Shea, 1987, p.1). Thus, the part-time students chose areas of investigation that could be applied in their professional lives and to issues related to teaching.

\section{Models of Learning: a cognitive science approach to understanding the learner}

During the late 1970s and the 1980s, the CALRG was influenced by the rise of cognitive science, which embraces a number of different disciplines: (see, e.g. https://plato.stanford.edu/entries/cognitive-science/), and, in particular, the application of artificial intelligence (AI) research. Such research was often located in the United States (e.g. Carnegie Mellon, MIT, Stanford) and in the UK in Edinburgh, Sussex, and the MRC Applied Psychology Unit in Cambridge. One founding member of the CALRG developed a "self-improving" quadratic tutor, (O'Shea, 1979), and another researcher (Eisenstadt, 1982) wrote a unit on AI for a cognitive psychology course.

Following AI-influenced approaches, some CALRG researchers were interested in developing production systems - computer programs consisting of a set of rules; ways of deciding different rules, and an interpreter to run the system - for psychological modelling, building theories about how people learn. To do this they collected student protocol data - where protocols are concerned with the process of carrying out a cognitive task (Ericsson and 
Simon (1980). This data could be used to construct production rule models which could then be used to predict the kinds of error that students were likely to make. Such models are valuable for examining learning but can also be embedded within tutoring systems (see for example O'Shea's "self improving" tutor, O'Shea, op. cit.).

Perhaps predictably, the fields and specific areas where such work was applied were those with sufficiently well-defined problems to benefit from such an approach. These included maths, physics problem solving, programming and graph interpretation skills. Many of the new approaches to teaching pioneered by The Open University related to STEM subjects and so there was a particular need to conduct research into teaching in these areas. This emphasis on STEM areas has persisted, and is reflected in Vision 4: Learners engage enthusiastically with STEM learning, although there has also been research in many non-STEM areas, including language learning, which is discussed briefly below. Overall, there has always been a strong interest in supporting student learning through designing instruction to help improve student performance, so the relationship with teaching is strong. Early goals also included theory development, e.g. understanding how physics problemsolving skills were developed.

Some developed models of learning that were used within courses. For example, O'Shea developed a computer game, modelled on the fraction buggy (Brown and Burton, 1978), which was embedded into teaching on an influential educational course for teachers: "Developing Mathematical Thinking". Indeed, cognitive science research had a significant impact on mathematics education more generally, see Siegler (2003).

CALRG research and evaluation have also fed into course design, sometimes directly and at other times more indirectly through studying students closely and developing an understanding of how the design of course materials influences students' understanding and learning. Good learning design is particularly important where students are learning at a distance. The production of Open University courses included a cycle of draft material which was commented on by the course team, which typically included both designers and media experts. In addition to the internal comments and suggestions, external readers would also read and comment on the materials. Some courses were developmentally tested - involving a more complete 'run-through', often by students.

As noted by Jones, Kirkup and Kirkwood (1992): “... it is particularly important to test out any element of practical work, whether it is a laboratory-style home experiment or the use of a computer, as students will be on their own if and when any problems occur" (p105). Their work on the Microcomputers for Schools project in the 1980s described how materials developed for teaching teachers were designed. They drew attention to the practical work texts, which were laid out in a three-column format, "where the first column gave the keypress required, the second gave a photograph of the screen display that appeared as a result of that action, and the third column provided a commentary" (p106). 


\section{The Beyond Prototypes Framework}

So far we have discussed how some of the educational technology research at the OU, conducted by members of CALRG, has fed back into and influenced the design of OU teaching material, its courses. However, there is also the larger question of how educational technology research, sometimes referred to as technology-enhanced learning (TEL) can be applied in education more generally and, when the research is focusing on development, how it can lead to useful and usable products.

A recognition that successful TEL innovations needed to be interdisciplinary led to the establishment of the ESRC (Economic and Social Research Council) TEL programme, which ran from 2008 to 2013. This programme awarded funding to eight TEL projects. Reflecting on these, Richard Noss, who directed the programme, wrote: "So the issue is this one: in general, despite the fact that all projects successfully designed and built effective prototypes of systems: the question is how to move from prototype to product." (Scanlon et al., 2013, p. 4). He continued: "So this report is concerned with how to move from academic research and innovative prototypes to effective and sustainable products and practices." (Scanlon et al, op. cit. p.5).

In order to do this, an interdisciplinary team of educational technologists analysed and evaluated TEL research and selected key examples to study in further detail. Drawing on these they developed a framework: "Beyond Prototypes", which is used to frame and consider both the historical and the contemporary research discussed in the book. The framework is based on four Key Insights from the research (see Scanlon et al, op. cit. pp. 5-8).

1 TEL involves a complex system of technologies and practices. In order to embed significant TEL innovation successfully, it is necessary to look beyond product development and pay close attention to the entire process of implementation.

2 Significant innovations are developed and embedded over periods of years rather than months. Sustainable change is not a simple matter of product development, testing and roll-out. Persistent intent is needed.

3 TEL innovation is a process of bricolage. This process includes informed and directed exploration of the technologies and practices required to achieve an educational goal. It involves experimentation to generate fresh insights, and creative use of available resources. It also requires engagement with a range of communities and practices.

4 Successful implementation of TEL innovation requires evidence that the projected educational goal has been achieved. Reliable evaluations must be carried out; their findings disseminated and acted on. Methods of evaluation are required that can be applied to processes of innovation and to institutional change, as well as those that can be applied to shifts in technology usage.

At the heart of the Beyond Prototypes model is Key Insight 1 - the 'TEL complex. The framework is represented in figure 1 which is reproduced below: 


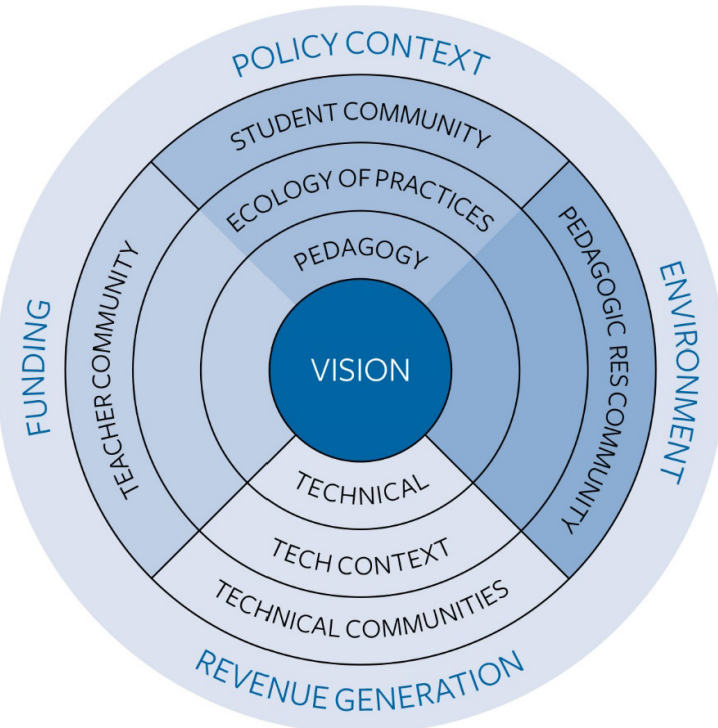

Figure 1.1: The Beyond Prototypes Model of the TEL Complex. Adapted from Figure 1 in Scanlon et. al. (2013) with thanks to the TLRP/TEL programme for permission to use this figure.

In order for TEL innovation to be successful, key elements must be considered. These are:

- pedagogy: "an extremely complex and distinctive process which involves both student and teacher engagement, delivering a set of educational services by means of specific channels." (Scanlon et. al., 2013 p.28);

- technical components that support the pedagogy in order to achieve the aim of enhancing learning in a specific way;

- the ecology of practices and technical context. These are important because any TEL will be implemented in a specific context. For example, internet coverage may be sporadic or unavailable (see, e.g. Gaved and Peasgood, 2017);

- the communities involved in the TEL complex, including students, teachers, researchers and technical developers or supporters.

Whilst it would be beyond the scope of this book to apply the complete framework for the research discussed, each chapter illustrates how aspects of the TEL complex work in practice. So, in Chapter 7 Rienties and Jones describe how the learning analytics research currently being undertaken involves a number of different communities in the University and how 'data wrangling' (a process which provides learning analytics information about University courses) 
involves a series of discussions with the academics involved in developing those courses.

Continuing work with the nQuire tool illustrates how persistent intent works (Key Insight 2). The nQuire tool was originally developed during a three-year project funded by the ESRC/TEL programme (2007-2010); Sharples et al (2015).

At the end of the successful project, a prototype tool was available. This required considerable further development, and was taken forward in a number of projects, (see e.g. Sharples, Aristeidou, Herodotou, Mcleod and Scanlon, 2019) as described by Scanlon and Herodotou in Chapter 9. In 2019 the nQuire tool was used by over 200,000 people as part of a citizen science project, Gardenwatch, to fill in a gap in information about the nature of UK gardens as habitats for wildlife.

Much of the emphasis of CALRG research has been on STEM subjects. However, the group has also been involved in research outside STEM and it continues this trajectory. Notable examples of research into how educational technology can support learning in other areas and contexts includes, for example, the use of mobile technologies to support language learning especially in informal contexts. This research has also been applied to support migrants' language learning, see, e.g. Kukulska-Hulme (2019) as noted in chapter 10. Another example is the work carried out by Charitonos on how microblogging (particularly the use of Twitter) can help to support and connect learning across museums and classrooms (see, for example Charitonos, 2019). A final example is Jones's work on affective issues in learning technologies, including using computer-mediated role play for investigating and supporting children's socio-emotive development and expression (Jones, 2010).

Even when research has originated in STEM contexts, it is often applied and further developed in numerous other non-STEM contexts, or in contexts where the types of scientific inquiries are very varied. One good example of this is the nQuire project, discussed by Sharples in the concluding chapter. The first nQuire project developed and evaluated an inquiry tool that could be used on mobile devices or on a computer to support school children's personalised scientific inquiries. Such inquiries included investigating whether an Urban Heat Island existed in the new city where one school was located. Other inquiries investigated healthy eating, bird feeding behaviour and how cheese rots. Parts of the investigations took part in the field, other parts at home and in the classroom.

This line of research is a good example of persistent intent. It has continued over a very long period, developing a platform that can support inquiries at a large scale, with a very broad definition of science.

The work on learning design, and our understanding of the learning process, which began in the 1970s (see chapter 6) is also applied to a very wide range of topics. In chapter 7, Rienties discusses its application to OU course or module design, whilst Ferguson (chapter 3) and Sharples (chapter 10) focus on different 
aspects of how research into the pedagogic process and learning design has fed into the development of MOOC platforms.

The remainder of this book is organised as follows: (this chapter is included in the list for completeness).

\section{Chapter 1: Introduction}

Ann Jones, Eileen Scanlon and Rebecca Ferguson

Introducing CALRG and giving the background to the group; setting out the visions, and placing them in context; introducing the framework and its importance for educational technology.

\section{Chapter 2: Teaching and Learning at Scale: Foundations Patrick McAndrew}

Studies of how distance learning can be supported by TEL and how these methods can scale. This chapter relates to Vision 1: Teams can successfully teach any number of students at a distance.

\section{Chapter 3: Teaching and Learning at Scale: Futures \\ Rebecca Ferguson}

Recent developments in this area, particularly massive open online courses (MOOCs.) This is the second chapter relating to Vision 1: Teams can successfully teach any number of students at a distance.

\section{Chapter 4: Accessible Inclusive Learning: Foundations}

Tim Coughlan, Kate Lister, Jane Seale, Eileen Scanlon and Martin Weller The development of open learning, and work on accessibility. This chapter relates to Vision 2: Learning is accessible for everyone.

\section{Chapter 5: Accessible Inclusive Learning: Futures}

Tim Coughlan, Kate Lister, Jane Seale, Eileen Scanlon and Martin Weller

Current work on open learning and accessibility and future directions. This is the second chapter relating to Vision 2: Learning is accessible for everyone.

\section{Chapter 6: Evidence-Based Learning: Foundations}

Ann Jones, Bart Rienties and Canan Blake

Developing a coordinated programme of research into ways computers can be used to improve the quality of education. This chapter relates to Vision 3: Teaching is adapted to meet learners' needs.

\section{Chapter 7: Evidence-Based Learning: Futures}

Bart Rienties and Ann Jones 
How this research programme has developed, with a focus on the relationship of learning design and learning analytics. This is the second chapter relating to Vision 3: Teaching is adapted to meet learners' needs.

\section{Chapter 8: STEM Learning: Foundations}

Eileen Scanlon, Christothea Herodotou, Denise Whitelock and Chris Edwards

Origins of work on learning and teaching STEM subjects at a distance. This chapter relates to Vision 4: Learners engage enthusiastically with STEM learning.

\section{Chapter 9: STEM Learning: Futures}

Christothea Herodotou, Eileen Scanlon and Denise Whitelock

Current and future work on areas including citizen science, inquiry learning and virtual field trips. This is the second chapter relating to Vision 4: Learners engage enthusiastically with STEM learning.

\section{Chapter 10: Visions for the Future of Educational Technology}

Mike Sharples

Drawing the themes together.

\section{References}

Brown, J. S. and Burton, R. R. (1978). Diagnostic models for procedural bugs, Cognitive Science Volume 2, Issue 2, April-June 1978. Pages 155-192.

Charitonos, K. (2019). Crossing over settings, practices and experiences: connecting learning in museums and classrooms. In: Looi, Chee-Kit; Wong, Lung-Hsiang; Glahn, Christian and Cai, Su eds. Seamless Learning: Perspectives, Challenges and Opportunities. Springer, pp. 111-137.

Crowther, Lord. (1969). Speech by Lord Crowther, first Chancellor of The Open University at the Presentation of the Charter, 23 ${ }^{\text {rd }}$ July 1969. Retrieved from: https://www.open.ac.uk/library/digital-archive/pdf/script/ script:5747089b4a53f

Eisenstadt, M. (1982). Design features of a Friendly Software Environment for Novice Programmers, in (Eds. Marc Eisenstadt, Mark T Keane and Tim Rajan), Novice Programming Environments: Explorations in HumanComputer Interaction and Artificial Intelligence, Routledge, UK.

Ericsson, K. A., \& Simon, H. A. (1980). Verbal reports as data. Psychological Review, 87(3), 215-251.

Gaved, Mark and Peasgood, Alice (2017). Fitting in Versus Learning: A Challenge for Migrants Learning Languages Using Smartphones. Journal of Interactive Media in Education, 2017(1), article no. 1. 
Jones, A. and Scanlon, E. (1981). A review of research in the CAL group: A report of the first annual conference, November, CALRG Technical Report No. 27, Open University, Milton Keynes.

Jones, Ann; Scanlon, Eileen and O'Shea, Tim eds. (1987). The Computer Revolution: New Technologies for Distance Teaching. Brighton: Harvester Press.

Jones, A., Kirkup, G. and Kirkwood (1992). Personal computers for distance learning (London, Paul Chapman).

Jones, Ann (2010). Affective issues in learning technologies: emotional responses to technology and technology's role in supporting socio-emotional skills. Journal of Interactive Media in Education.

Kukulska-Hulme, A. (2019). Mobile Language Learning Innovation Inspired by Migrants. Journal of Learning for Development - JL4D, 6(2) pp. 116-129.

O'Shea, T (1979). International Journal of Man-Machine Studies Volume 11, Issue 1, January 1979, Pages 97-124.

Perry, W. (1969). Establishment of an Applied Educational Science Unit, Council Paper C/II/3. Milton Keynes: Open University.

Scanlon, Eileen; Sharples, Mike; Fenton-O'Creevy, Mark; Fleck, James; Cooban, Caroline; Ferguson, Rebecca; Cross, Simon and Waterhouse, Peter (2013). Beyond prototypes: Enabling innovation in technology-enhanced learning. Open University, Milton Keynes.

Sharples, Mike; Scanlon, Eileen; Ainsworth, Shaaron; Anastopoulou, Stamatina; Collins, Trevor; Crook, Charles; Jones, Ann; Kerawalla, Lucinda; Littleton, Karen; Mulholland, Paul and O'Malley, Claire (2015). Personal inquiry: orchestrating science investigations within and beyond the classroom. Journal of the Learning Sciences, 24(2) pp. 308-341.

Sharples, Mike; Aristeidou, Maria; Herodotou, Christothea; McLeod, Kevin and Scanlon, Eileen (2019). Inquiry learning at scale: pedagogyinformed design of a platform for citizen inquiry. In: Proceedings of the Sixth (2019) ACM Conference on Learning @ Scale - L@S '19, ACM Press, New York, NY, USA, article no. 29.

Siegler, R. S. (2003). Implications of cognitive science research for mathematics education. In Kilpatrick, J., Martin, W. B., \& Schifter, D. E. (Eds.), A research companion to principles and standards for school mathematics (pp. 219233). Reston, VA: National Council of Teachers of Mathematics. 